\title{
Microfabricated gas sensor systems with sensitive nanocrystalline metal-oxide films
}

\section{Journal Article}

Author(s):

Graf, M.; Gurlo, A.; Barsan, N.; Weimar, U.; Hierlemann, Andreas (DD

Publication date:

2006

Permanent link:

https://doi.org/10.3929/ethz-b-000001302

Rights / license:

In Copyright - Non-Commercial Use Permitted

Originally published in:

Journal of Nanoparticle Research 8(6), https://doi.org/10.1007/s11051-005-9036-7 


\title{
Microfabricated gas sensor systems with sensitive nanocrystalline metal-oxide films
}

\author{
M. Graf ${ }^{1, *}$ A. Gurlo ${ }^{2}$, N. Bârsan ${ }^{2}$, U. Weimar ${ }^{2}$ and A. Hierlemann ${ }^{1}$ \\ ${ }^{1}$ ETH Zurich, Physical Electronics Laboratory, HPT-H8, CH-8093, Zurich, Switzerland; ${ }^{2}$ Institute \\ of Physical and Theoretical Chemistry, University of Tübingen, Auf der Morgenstelle 8, D-72076, \\ Tübingen, Germany; *Author for correspondence (Tel.: +41-44-633-3494; E-mail: mgraf@phys.ethz.ch)
}

Received 22 April 2005; accepted in revised form 21 August 2005

Key words: CMOS, deposition, gas sensor systems, metal oxides, microhotplates

\begin{abstract}
This article gives an overview on recent developments in metal-oxide-based gas sensor systems, in particular on nanocrystalline oxide materials deposited on modern, state-of-the-art sensor platforms fabricated in microtechnology. First, metal-oxide-based gas sensors are introduced, and the underlying principles and fundamentals of the gas sensing process are laid out. In the second part, the different deposition methods, such as evaporation, sputtering, sol-gel techniques, aerosol methods, and screen-printing, and their applicability to micro-scale substrates are discussed in terms of their deposition precision, the achievable layer thickness, as well as with regard to the possibility to use pre-processed materials. In the third part, microsensor platforms and, in particular, semiconductor- and microelectronics-based sensor platforms, which have been fabricated in, e.g., standard CMOS-technology (CMOS: complementary metal-oxide semiconductor), are briefly reviewed. The use of such microfabricated sensor platforms inevitably imposes constraints, such as temperature limits, on the applied nanomaterial processing and deposition methods. These limitations are discussed and work-arounds are described. Additionally, monolithic sensor systems are presented that combine microtransducers or microhotplates, which are coated with nanomaterials, with the necessary control and driving electronics on a single chip. The most advanced of such systems are standalone units that can be directly connected to a computer via a digital interface.
\end{abstract}

\section{Introduction}

Since Heiland (Heiland, 1957), Bielanski (Bielanski et al., 1957) and Seiyama (Seiyama et al., 1962) discovered the gas sensing capabilities of metal oxides, and since Taguchi developed metal-oxidebased sensors into an early industrial product (Taguchi-type sensors, Taguchi 1971), a lot of work and efforts have been invested to further develop those sensors, to optimize their sensing performance, to bring down their costs, and to simplify their use in a real-world environment.
There are currently several companies that market metal-oxide-based gas sensors, for example Figaro (www.figarosensor.com), FIS (www.fisinc.co.jp), Microchemical Systems, MICS (www.microchemical.com), City Technology (www.citytech.com), AppliedSensor (www.appliedsensor.com), Umwelt sensortechnik GmbH, UST (www.umweltsensortechnik.de), and Paragon (www.paragononline1.de).

Metal-oxide-based gas sensors more and more penetrate also mass-market applications, which include, e.g., automotive applications (cabin air 
quality control) as well as more traditional fields such as toxic- and explosive-gas alarms (Marek et al., 2003). A lot of efforts are also invested in developing new applications such as in-door air quality monitoring in residential and office buildings.

Though many different metal oxides have been investigated as gas sensor materials, tin oxide $\left(\mathrm{SnO}_{2}\right)$ is still the most commonly used material (Barsan et al., 1999). An overview over the gas sensor properties of the many different metal oxides and a wealth of additional examples of applications are also given in recently published reviews (Eranna et al., 2004; Pierce et al., 2004).

These sensitive metal-oxide materials include wide-bandgap semiconducting oxides such as tin oxide, gallium oxide, indium oxide, or zinc oxide. In general, gaseous electron donors or acceptors adsorb on the metal oxides and form surface states, which can exchange electrons with the semiconductor metal oxide. An acceptor molecule will extract electrons from the metal-oxide semiconductor and thus decrease its conductivity. The opposite holds true for an electron-donating molecule. A space charge layer will thus be formed. By changing the surface concentration of donors/acceptors, the conductivity of the space charge region is modulated so that the conductivity of metal-oxide semiconductor materials changes in response to analyte gas concentration changes. These chemically induced changes can then be transduced into electrical signals by means of, e.g., simple electrode structures (conductivity measurements).

The overall conductivity in a metal-oxide-based sensor is determined by the analyte gas surface reactions, the subsequent charge transfer processes between adsorbed gaseous species and the semiconductor oxide material, and the transport mechanisms within the sensitive oxide layer. For porous, polycrystalline metal oxides, the best way to describe the conduction process is to consider that the free charge carriers (electrons or holes) must overcome the intergranular barriers (Figure 1a) that result from band bending at the adjacent surfaces of neighboring grains (Williams, 1987; Madou \& Morrison 1989; Bârsan \& Weimar, 2001). The barrier heights and the occupancies of the surface states are altered by the adsorption of analyte molecules from the gas phase. The overall conductivity in polycrystalline samples hence includes contributions from the individual crystallites, the grain boundaries, insulating components such as pores, and the contacts (Figure 1b). Therefore, the conduction mechanism in ceramic polycrystalline samples is difficult to analyze, and a variety of data and models has been published (Williams, 1987; Madou \& Morrison, 1989; Bârsan \& Weimar, 2001).

The most extensively investigated material, tin oxide, is oxygen-deficient and, therefore, an n-type semiconductor since oxygen vacancies act as electron donors. In clean air, oxygen, which traps free electrons by its electron affinity, and water are absorbed on the tin oxide particle surface forming a potential barrier in the grain boundaries. This potential barrier restricts the flow of electrons and thus increases the resistance. When tin oxide is exposed to reducing gases such as carbon monoxide, the surface adsorbs the gases, and some of the oxygen is removed by reaction with water and oxygen at the surface. This lowers the potential barrier, thereby reducing the electric resistance. The reaction between gases and surface oxygen depends on the sensor temperature, the gas involved, and the sensor material (Williams, 1987; Madou \& Morrison, 1989; Bârsan \& Weimar, 2001).

Semiconductor metal-oxide sensors usually are not very selective, but respond to almost any analyte (carbon monoxide, nitrogen oxide, hydrogen, hydrocarbons). One method to modify the selectivity pattern includes surface doping of the metal oxide with catalytic metals such as platinum, palladium, gold, and iridium (Williams, 1987; Madou \& Morrison, 1989; Bârsan et al., 1999; Bârsan \& Weimar, 2001). Surface doping improves the sensitivity to reducing gases, reduces the response time and operation temperature and changes the selectivity pattern.

The conduction mechanism in polycrystalline metal oxides strongly depends on the morphology of the layer and the grain size of the metal oxides (Bârsan \& Weimar, 2001). Most modern sensors operate in a regime, in which the overall conductivity is determined by nanocrystalline sensing materials. Although the effect of the grain size on the sensing performance is still under debate (Xu et al., 1991; Rothschild \& Komem, 2004), it has been shown that a decreasing grain size enhances the performance of the sensors, i.e., increases the sensor signals and, correspondingly, the sensor sensitivity. The reasons for this increase are most 
(a)
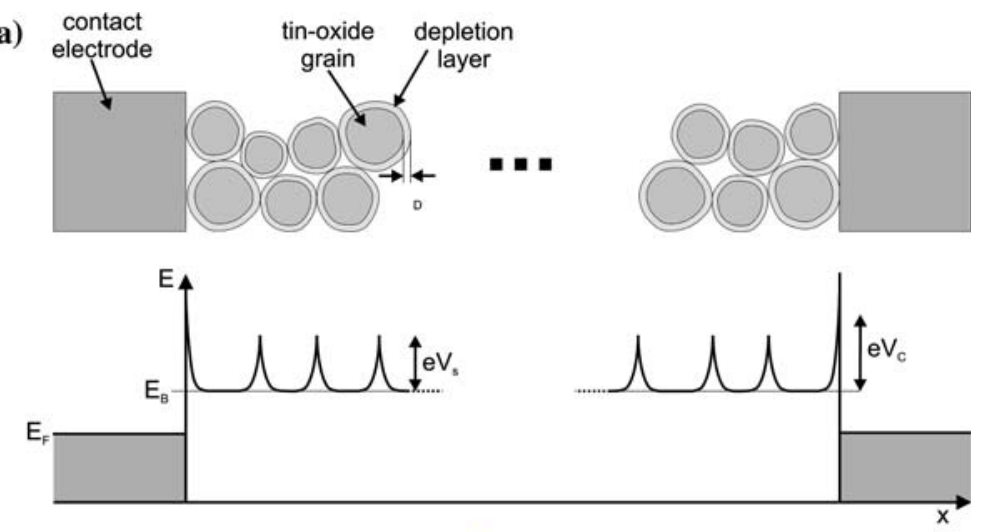

(b)

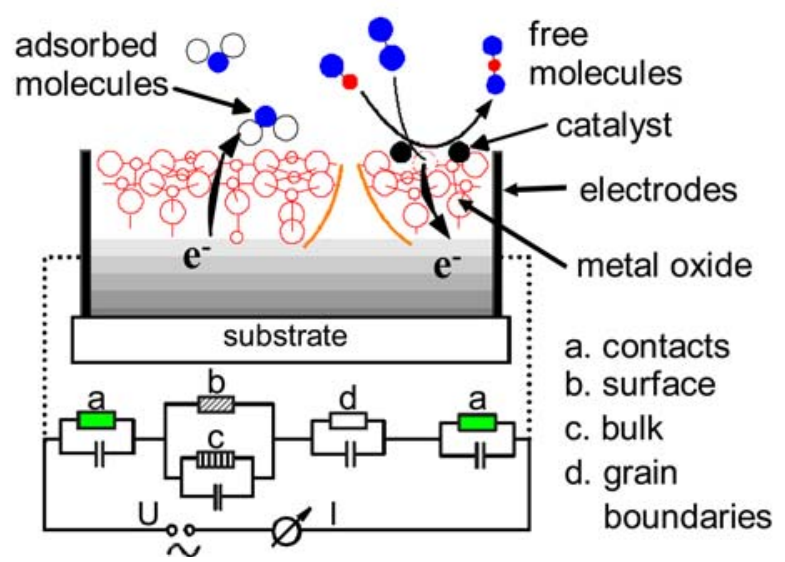

Figure 1. (a) Schematic representation of a porous nanocrystalline sensitive metal-oxide layer and one-dimensional representation of the electronic band structure. An inter-grain band bending $\left(\mathrm{eV}_{\mathrm{s}}\right)$ occurs as a consequence of surface contact phenomena. A band-bending also occurs at the grain-electrode contact $\left(\mathrm{eV}_{\mathrm{c}}\right) . E_{\mathrm{B}}$ denotes the lower conduction band limit in the bulk tin oxide, and $E_{\mathrm{F}}$ is the Fermi-level in the metal electrode. (b) Schematic representation of a metal-oxide-based sensor (tin oxide as sensitive layer), of the different contributions (contacts, surface, bulk and grains) to the overall conductivity and of the respective equivalent circuits.

probably due to the enlarged overall active surface area of the sensing layer as a consequence of the small grain size (better surface to volume ratio) so that the relative interactive surface area is larger, and the density of charge carriers per volume is higher. However, it has to be noted that the overall picture is rather complex, and that the observed effects do not only depend on the particle size but also on the particle agglomeration into larger grains, on the accessible surface area, on the degree of agglomeration, the layer morphology and porositiy. Several publications provide a good overview on existing concepts and models in this field (Bàrsan \& Weimar, 2001; Rothschild \& Komem, 2004).

The most advanced and best-performing gas sensors exhibit nanostructured materials deposited as thick porous films on the transducer surface carrying the electrodes. The sensors based on thin sensing oxide films seem to have fundamental sensitivity limitations regardless of the deposition method (Bârsan \& Weimar, 2001). State-of-the-art sensors are based on pre-processed oxide powders that have been previously stabilized by high-temperature annealing. These pre-processed powders can be obtained via different chemical routes and they can be additionally functionalized by adding small quantities of noble metals in the form of surface additives (Bârsan et al., 1999; Graf et al., 2004c).

A significant fraction of the overall research and development efforts in metal-oxide-based gas sensors is currently directed toward sensor miniaturization (Simon et al., 2001; Hierlemann \& Baltes, 
2003a; Hierlemann et al., 2003b), which requires the development of sensitive-layer deposition techniques with micrometer precision that are compatible to the microfabrication processes (Gardner et al., 1995; Cerdà et al., 2001; Heule \& Gauckler, 2001; Semancik, et al., 2001; Puigcorbe et al., 2002; Aronova et al., 2003; Friedberger et al., 2003; Heule \& Gauckler, 2003; Riviere et al. 2003; Savage et al., 2003; Su et al., 2003; Wöllenstein et al., 2003a). Another research thrust is the full integration of microfabricated or MEMS-type (MEMS: Micro Electro Mechanical Systems) chemical sensors with the associated driving and signal conditioning electronics on a single chip, preferably in CMOS technology (CMOS: complementary metal-oxide semiconductor), as will be discussed in more detail below (Barrettino et al., 2004; Graf et al., 2004a, b, c).

At present, one of the most common micromachined components of gas sensors is the so-called microhotplate ( $\mu$ HP) (Semancik et al., 2001; Simon et al., 2001). Such a $\mu$ HP for metal-oxide-based gas sensing consists of a thermally isolated stage, which has been fabricated using microtechnological processes. The integrated heating element helps to achieve the typical sensor operation temperature on the order of $300-400^{\circ} \mathrm{C}$, and the temperature sensor is used to monitor the microhotplate temperature. In case of chemoresistive signal readout, two or more electrodes are fabricated to enable resistance or impedance measurements of the sensing material. Microhotplates offer low power consumption, the possibility to apply defined temperature protocols owing to their little thermal mass (Heilig et al., 1997; Ding et al., 2001), small area, simple microelectronics-derived packaging, and the possibility of low-price mass fabrication.

Most of those state-of-the-art metal-oxide-based microsensors rely on nanocrystalline materials deposited as thick porous films so that suitable metal-oxide synthesis and deposition methods had to be developed (Simon et al., 2001). The nanoparticle production methods for sensor materials have to satisfy various requirements. The grain or particle size and crystallinity have to be carefully controlled, and the possibility to add noble metal dopants already during the nanoparticle processing should be considered.

Various synthesis methods of metal-oxide nanoparticles of different shapes (e.g., spherical or rod-like) and morphology have been developed for gas-sensing applications. Many different metal oxides are nowadays available in unprecedented small particle sizes - down to $2 \mathrm{~nm}$ - and high crystallite quality (Pinna et al., 2004). Moreover, most of the metal oxides that are used for gas sensing (i.e., $\mathrm{SnO}_{2}, \mathrm{WO}_{3}, \mathrm{In}_{2} \mathrm{O}_{3}$ ) are commercially available as nanopowders from large and small companies that supply chemicals (www.sigmaaldrich.com, www.alfa.com, www.remy-hamburg.de). Synthesis methods of submicrometer metal-oxide particles for gas sensing applications have been summarized (Kennedy et al., 2003; Sahm et al., 2004; Shimizu, et al., 2004 and references therein) and reviewed in several publications (Eranna et al., 2004). For example, nano-size $\mathrm{SnO}_{2}$ particles have been synthesized by sol-gel methods, precipitation from solutions, gas-phase condensation, decomposition of organometallic precursors, oxidation of metallic tin, hydrothermal treatment of colloidal solutions, hydrothermal synthesis (Pinna et al., 2004), laser ablation, (Kennedy et al., 2003), mechano-chemical processing, template synthesis (mesoporous structures; (Shimizu et al., 2004), thermal decomposition (Guidi et al., 2002), and flame spray pyrolysis (Sahm et al., 2004).

However, sensor miniaturization does not only benefit from the synthesis of nano-size metal-oxide particles but, in turn, requires the development of high-performance deposition methods and techniques that are compatible with the transducer fabrication technology (micromachining, etc). In most cases, a locally defined patterning of the sensitive layer with a spot size of $100 \mu \mathrm{m}$ and at micrometer precision is necessary. Temperature restrictions for the deposition as well as the posttreatment/annealing may result from the use of microelectronic transducers and substrates; an upper temperature limit of approximately $400^{\circ} \mathrm{C}$ holds, e.g., for using CMOS substrates with integrated electronics. The small film thickness and the small lateral spot size are a consequence of using an as small as possible quantity of the sensing material, since the deposited material affects the thermal homogeneity of the microhotplate, and increases both, its thermal time constant and its power consumption (Puigcorbe et al., 2002; Graf et al., 2005a).

New developments in deposition methods that are compatible with micromachined substrates are briefly discussed in the next section ('Recent 
developments in the deposition methods') and are summarized in Tables 1-4. The most recent developments in gas sensor microsystems that make use of nanocrystalline metal-oxide materials are then described in the section 'Gas sensor microsystems and CMOS-based gas sensor microsystems'.

\section{Recent developments in the deposition methods}

The techniques currently used for the deposition of metal oxides sensing films on micromachined substrates (Figure 2) can be categorized into (I) sputtering/evaporation methods (e.g. magnetron sputtering, e-beam evaporation, rheotaxial growth and oxidation - RGTO) (Table 1), (II) aerosol methods (chemical vapor deposition, CVD, flamespray pyrolysis, FSP) (Table 2), (III) methods based on the sol-gel technique (spin-coating, dropcoating, spray-coating, micromolding in capillaries, dip-pen nanolithography, DPN) (Table 3) and (IV) 'classical' methods for thick-film deposition (screen-printing and drop deposition) (Table 4). Categories (I) and (II) will be treated jointly in the section 'Evaporation, sputtering and flame-spray methods', (III) in 'Sol-gel-based methods', and (IV) in 'Classical thick-film deposition technology'. More details can be found in monographs (Reed, 1986; Brinker \& Scherer, 1990; Kodas \& Hampden-Smith, 1999).

Most of the above-mentioned methods either rely on masking processes (shadow mask for evaporation/sputtering and aerosol deposition, screen for screen-printing, photoresist mask for all lift-off-based processes, patterned PDMS mold for micromolding) or on suitable 'functionalization' or activation of the substrate ('site-selective' methods) to achieve a locally defined deposition of a sensitive material on the substrate.

Classical microtechnological approaches include the use of masks (shadow masks as well as photoresist masks) combined either with classical physical deposition (sputtering, evaporation) (Demarne \& Grisel, 1993; Wöllenstein et al., 2003a; Stankova et al., 2004) or with liquid-based deposition, i.e. spray deposition ('pulverization') (Jimenez et al., 2001, 2002) or spin-coating (Chung et al., 2000).

In the so-called 'lift-off' process a photoresist is exposed to UV-light through a mask. The mask

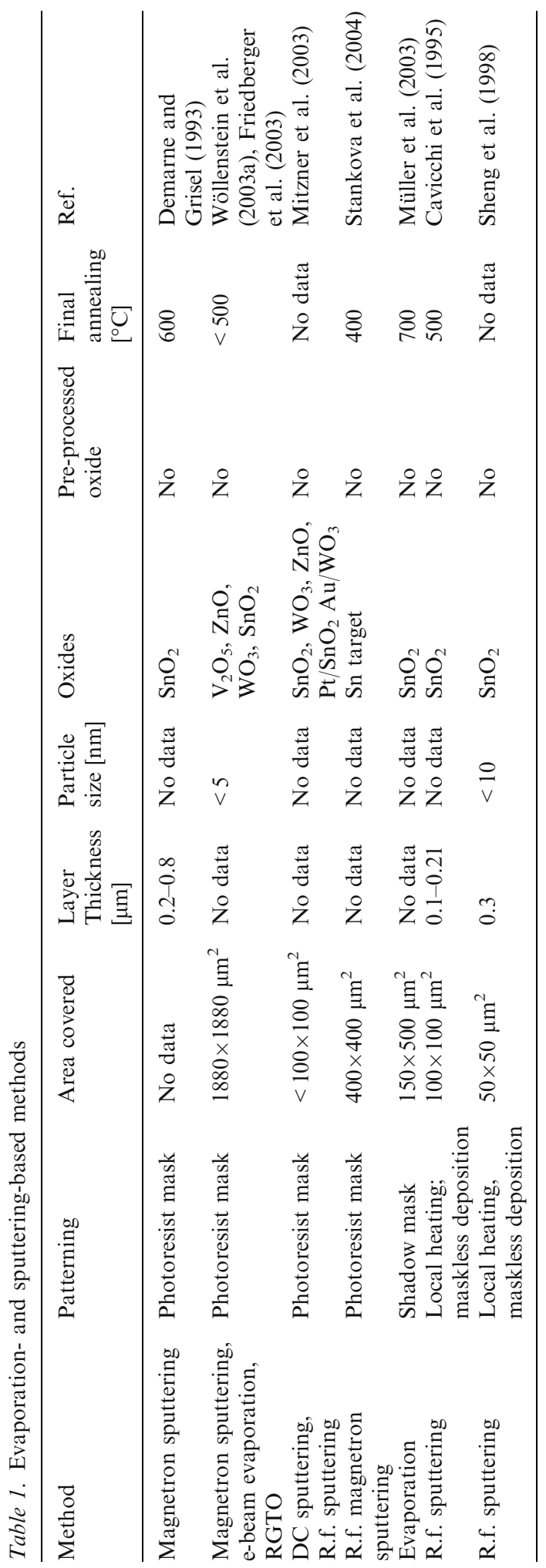




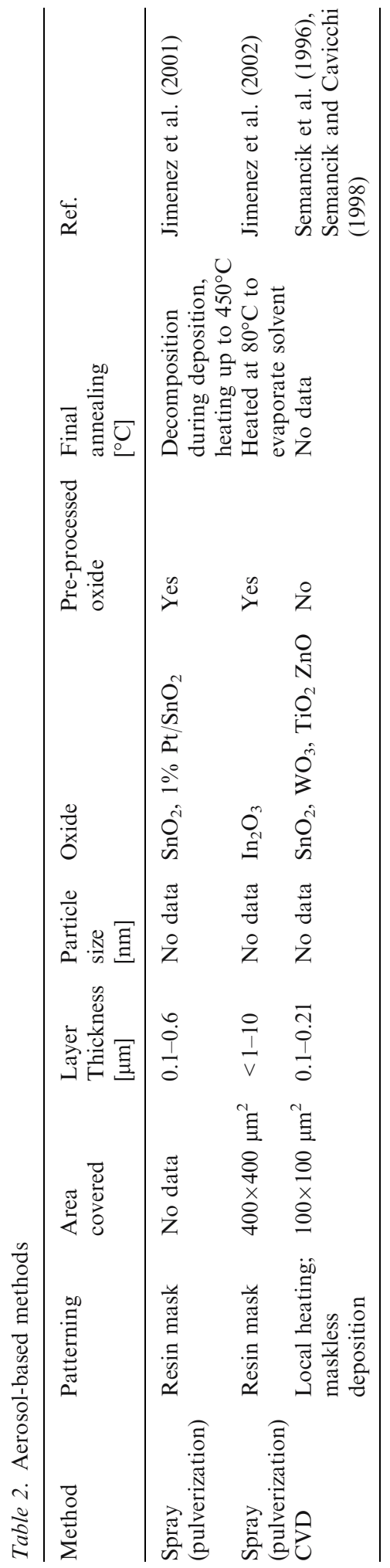

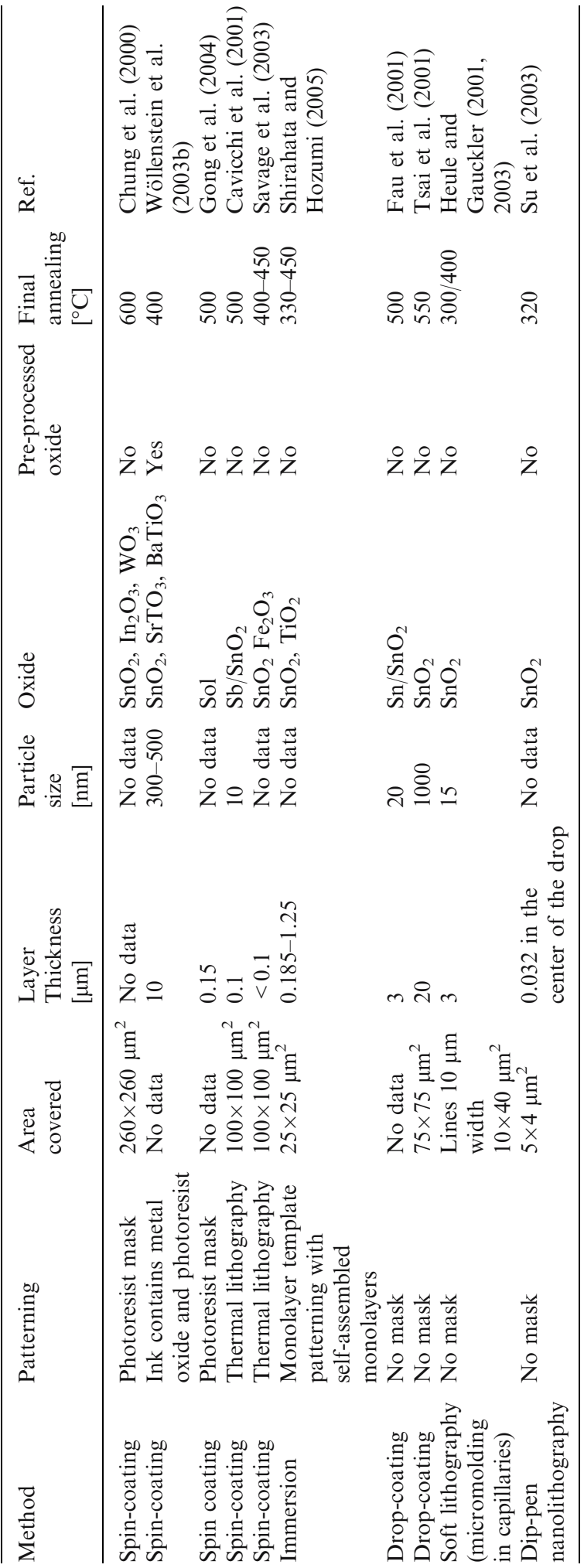




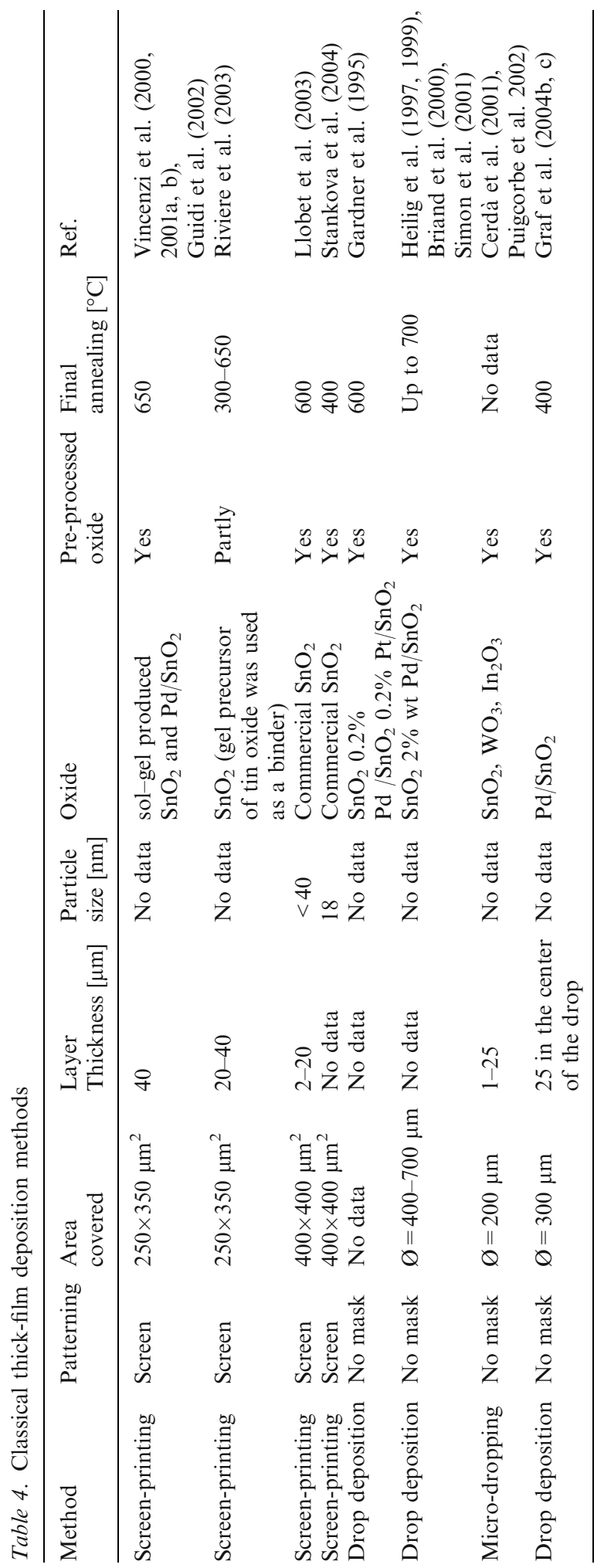

defines adhesive (light exposure) and nonadhesive (no light exposure) areas for the subsequent sensitive-layer deposition step. After developing the photoresist, it can be dissolved in the exposed area, whereas the nonirradiated (positive) photoresist remains intact. The sensitive layer is then applied to the substrate and adheres to the substrate surface in the exposed area or sits on top of the photoresist in the area that has not been exposed to light during the photolithography step. By applying an organic solvent to the substrate, the photoresist is dissolved and removed along with the sensitive material, which is on top of the photoresist. The sensitive material hence sticks only to the area, which has been exposed to light during the first masking step. The metal oxide layers must then survive the post-lift-off processing steps, such as etching or annealing, and should also not be contaminated during any of the post-processing steps.

Alternative approaches include so-called 'siteselective' methods (a brief summary of site-selective techniques is given in an overview on the use of microhotplate platforms for chemical sensor research by Semancik et al., 2001). They are based on micropatterning of a substrate, which can be achieved either by modification of the wetting properties of the substrate (Shirahata \& Hozumi, 2005) or by utilizing local heating for site-selective deposition (Cavicchi et al., 1995; Semancik et al., 1996; Semancik \& Cavicchi, 1998; Sheng et al., 1998; Cavicchi et al., 2001; Savage et al., 2003). The latter can be done either maskless ('self-lithographic approach') or by using conventional thermal resists (thermal lithography - thermal resists are removed by heating). In both cases, the deposition process can be electronically controlled in-situ owing to the electrical conductivity of the growing films of semiconducting metal oxides.

Only drop-coating-based methods (drop-coating, microdropping, drop deposition, and dip-pen nanolithography) do not require any additional patterning and masking and can be used to achieve a locally defined deposition of the sensing film exclusively in the active area of the transducer. The different drop-coating-based methods differ either in the liquid matrix that is used for the deposition (colloidal dispersions in 'classical' drop-coating methods, viscous suspensions in drop-deposition methods), or in the deposition tools (microinjector 

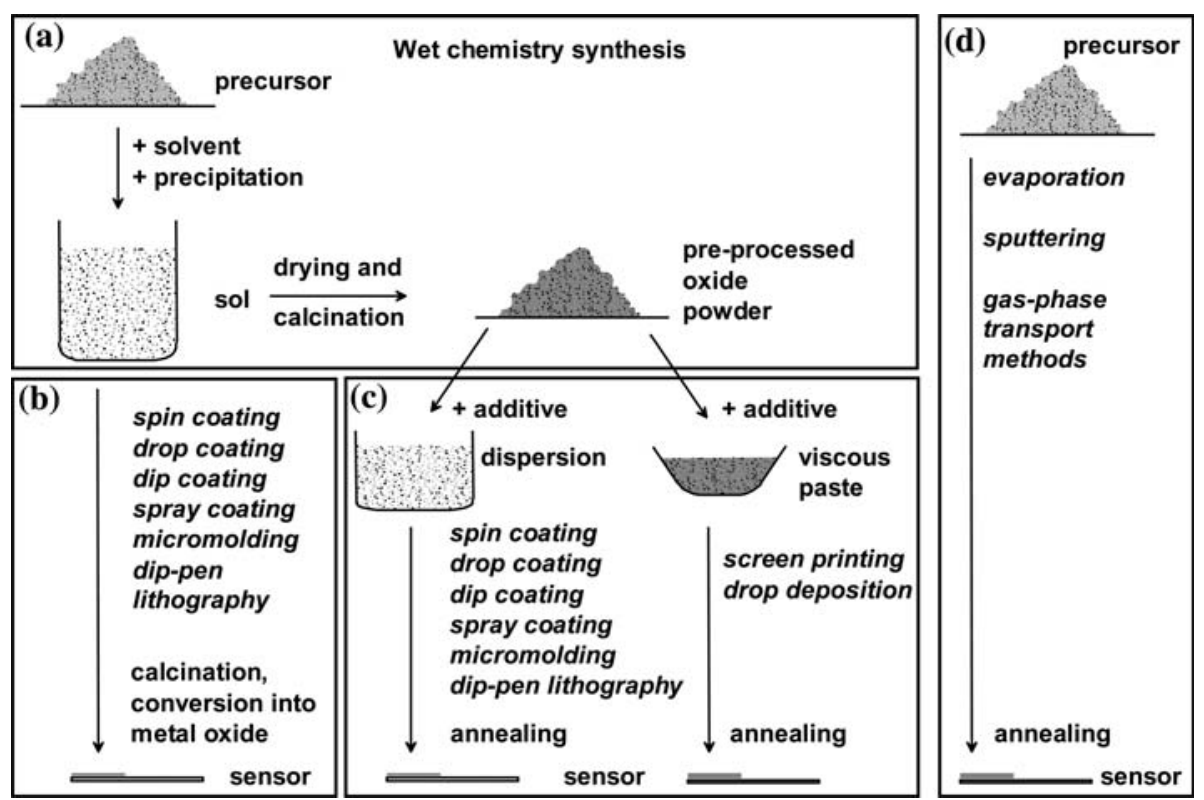

Figure 2. Overview over deposition techniques. (a) Wet chemistry methods (precipitation and sol-gel method) are shown as an example for synthesis of nanocrystalline metal oxide. (b) Classical sol-gel-based deposition. (c) Methods for the deposition of pre-processed metal oxides. (d) Evaporation, sputtering and gas-phase-transport-based techniques (CVD and FSP). For details, see text.

for microdropping, AFM tip in dip-pen nanolithography).

For satisfactory reproducibility, an extremely good control of the properties of the pastes or suspensions that are used for the deposition is mandatory. Drop-coating methods are used in industry for the deposition of metal-oxide films on micromachined platforms. They encompass, e.g., drop-coating using a suspension of a pre-processed oxide (see www.appliedsensor.com), or drop-coating from a colloidal solution (see www.microchemical.com).

Only few of the methods, namely spin-coating, drop-coating and drop-deposition, spray-coating, screen-printing, micromolding in capillaries, and dip-pen nanolithography enable the deposition of pre-processed oxide powders, i.e., powders that have been stabilized by high-temperature annealing and/or functionalized by adding, e.g., small quantities of noble metals. These methods allow for the deposition of the sensitive material in lateral dimensions down to several microns and at thicknesses down to several tens of nanometers (DPN). All of them are wet-chemistry-based methods and require a suitable formulation of the suspensions/dipersions as well as of the pastes (e.g., solid loading, viscosity) used for the deposition. Furthermore, the mean grain size (and grain size distribution) of the metal-oxide powder must be in the nanometer range for the deposition of such small-spot layers. The nanocrystalline nature of the oxide materials leads to a drastic increase in the specific surface area of the powder and significantly changes the surface properties of the material such as the point of zero charge (PZC), the wettability, and the reactivity. This entails additional challenges to find suitable layer and layer precursor formulation technologies.

\section{Evaporation, sputtering and flame-spray methods}

Combinations of the physical deposition methods (sputtering as well as evaporation techniques) with photolithographic technologies belong to the classical microtechnological approaches (Table 1). One example of the so-called 'self-lithographic' approaches include the thermally-activated chemical vapor deposition (CVD) and radiofrequency (rf) sputtering, which lead to locally defined layer deposition only in the heated areas of the substrate (Cavicchi 
et al., 1995). However, these methods have several limitations related to the deposition temperature, the achievable thickness of the deposited sensing layers (less than $1 \mu \mathrm{m}$ ), and the stoichiometry of the deposited materials (Table 1). The latter is related to the post-deposition annealing temperature, which is limited to $400-600^{\circ} \mathrm{C}$, and is not high enough to obtain fully stable oxides. The functionalization of the sensing materials by adding either dopants or catalytic materials is difficult and, in most cases, even impossible. Another issue is the precise patterning of the sensitive material at micrometer resolution. Moreover, sputtering and evaporation are not suitable for the deposition of pre-processed oxides.

Some of these issues can be addressed by the use of sol-gel and CVD techniques. Limitations of chemical methods (CVD) include the availability of suitable precursor chemistry, the reagent gas composition, and the precursor partial pressure to control the composition and microstructure of the deposited films (Taylor \& Semancik, 2002).

Recently, an advancement in the fabrication of thick porous sensing films through direct deposition of nanoparticles onto sensor substrates in a single process step ( $<5 \mathrm{~min}$ ) has been presented (Mädler et al., 2005). A flame spray pyrolysis (FSP) reactor was used to produce monodisperse $\mathrm{SnO}_{2}$ particles, which were either pure or functionalized with platinum $(0.2-2 \mathrm{wt} \%)$. Upon formation in the flame, the particles are directly (in situ) deposited/sprayed onto sensor substrates. The functionalization of $\mathrm{SnO}_{2}$ nanoparticles with platinum was also performed in the same single step during the deposition of the sensing films.

The synthesis and deposition of the sensing layer material in all above-mentioned methods (sputtering, evaporation, CVD and FSP) is done in one step, i.e., the particles are immediately deposited onto the sensor substrates upon formation ('synthesis'), which renders these methods unsuitable for the deposition of pre-processed oxides.

\section{Sol-gel-based methods}

Sol-gel techniques that capitalize on the specific properties of nanocrystalline particles to form stable dispersions and suspensions can be applied in different ways:

(i) Spray-coating: The colloidal dispersion of a pre-processed metal oxide (or a sequence of precursor solutions) is sprayed onto the substrate. In most cases, a sol is sprayed on the substrate surface using a spray gun, which is usually moved across the substrate;

(ii) Drop-coating: Dropping the colloidal dispersion of the pre-processed metal oxide (or a sequence of precursor solutions) onto the substrate. A drop is placed on the substrate surface using a micropipette or microinjector;

(iii) Spin-coating: Spin-deposition of the colloidal dispersion of the pre-processed metal oxide (or a sequence of precursor solutions) onto the substrate, whereby the thickness of the deposited gel layer can be controlled by varying the revolution rate.

The final coating thickness is, in any event, a function of the liquid matrix viscosity, i.e., the chemical composition of the sol, the time and temperature, at which the sol is prepared, and some technical parameters, such as the substrate revolution rate or movement speed. The spincoating technique requires even substrates in order to achieve a constant layer thickness over the whole substrate. In contrast, spray- as well as drop-coating methods do not require any defined substrate geometry/morphology. During spray coating, the formed droplets have to wet the substrate, then spread out and form a smooth layer of constant thickness. However, one of the problems associated with the spray-coating procedure is that the solvent is evaporating from the droplets already on the way to the substrate during spraying. Owing to a usually broad droplet size distribution, chemically different compositions of the droplets may occur so that the wetting of the substrate may vary, and inhomogeneous layers of high surface roughness may be formed.

Spin-coating techniques can be used in combination with thermal lithography (Savage et al., 2003) for site-selective deposition. Oxide layers deposited from colloidal solutions attach only to heated areas through controlled-rate drying and subsequent evaporation of the solvent or through a sol/gel phase transition.

Another development of thermal lithography in combination with a spin-coating technique uses the wetting properties of the substrate to achieve local deposition. To pattern the substrate (i.e., to make it hydrophobic), thin films of (tridecafluoro1,1,2,2-tetrahydro-octyl)trichlorosilane (TFS) or 
hexyltrichlorosilane (HTS) on surfaces serve as thermal resists so that heating of specific structures removes the organosilane films from the heated areas (regions heated above $400^{\circ} \mathrm{C}$ ) generating hydrophilic surfaces, while TFS films in unheated areas were unaffected and remained hydrophobic. Tin dioxide spin-coated on the thermally patterned arrays then adheres only to the hydrophilic regions and is repelled from the hydrophobic areas covered with the TFS films (Savage et al., 2003). This method offers a straightforward possibility for the deposition of pre-processed metal oxides. However, limitations include the film thickness (less than $1 \mu \mathrm{m}$ ) and the crystallinity of the final material. A modification of this methodology includes a fabrication of metal oxide, e.g., $\mathrm{SnO}_{x}$, microstructures on a flexible polymer substrate (polyimide) through controlled monolayer template micropatterning of the substrate with selfassembled monolayers followed by immersion in an aqueous solution of tin chloride (Shirahata \& Hozumi, 2005).

The fabrication of miniaturized tin oxide arrays based on a micromolding technology has been presented by Heule and Gauckler (2001, 2003). This method is pushing the limits of miniaturization for metal-oxide-based gas sensors by, e.g., reducing the sensing layer area to $10 \times 30 \mu \mathrm{m}^{2}$. This drastic area reduction was made possible by using a micromolding technique with capillaries, which belongs to the soft-lithography methods. For micromolding in capillaries, a patterned $(410 \mu \mathrm{m}-$ wide channels) polydimethylsiloxane (PDMS) mold is placed upside down on a substrate. The stamp is opened along the side, where a droplet of the colloidal dispersion can be applied, which then spontaneously fills the capillaries as a consequence of capillary forces.

An efficient approach to further downsize chemical sensors that explores the limits of miniaturization for metal-oxide-based gas sensors has been described by $\mathrm{Su}$ et al. (2003). This method is exploiting the capabilities of dip-pen nanolithography (DPN) for site-specific and multiple ink patterning, and capitalizes on the versatility of sol-gel synthesis to prepare suitable sol inks. Dip-pen nanolithography is based on the controlled transfer of ink molecules from an ink-coated tip of an atomic-force microscope to a substrate. Moreover, a refined ink-coating and patterning method has been developed, which combines micro-pen patterning and DPN and provides more control and flexibility in comparison to the previously described methods: $5 \mu 1$ droplets of sol inks are deposited on a substrate to form millimeter-scale ink reservoirs. An AFM tip controlled by a motor touches the surface of the reservoir. The quantity of adsorbed ink can be varied by controlling the tip contact time and the immersion depth. The quantity of ink adhering to the tip can also be modified by lowering the coated tip onto an ink-free area on the substrate. The ink-coated tip is used to create DPN patterns on a substrate carrying prefabricated electrodes (Su et al., 2003).

\section{Classical thick-film deposition technology}

Screen printing belongs to the most established methods of thick-film deposition. For screenprinting of a continuous homogeneous sensitive layer, the pre-processed metal-oxide powder has to be mixed into a homogeneous paste with an appropriate organic carrier until the desired consistency and viscosity of the paste is achieved. In a next step, a rubber squeegee is used to press the paste through a screen, which works as a mask for the paste transfer onto the substrate. Finally, the organic binders of the film are removed during the annealing ('firing') procedure, which renders the sensitive layer mechanically stable and provides strong material adhesion to the substrate.

The combination of new types of screens, computer-based alignment facilities and customdesigned stencils enables high-resolution and lowforce depositions so that screen-printing can be used for material deposition onto fragile micromachined substrates (Vincenzi et al., 2001a, 2001b). Riviere et al. (2003) describe a method of forming sensitive layers on microhotplates using screen-printing and novel ink formulations. The inorganic precipitable component and the inorganic binders of the ink have been substituted with a tin oxide gel. The gel facilitates the control of the rheological properties and the control of the mechanical adhesion.

As already mentioned, drop deposition from viscous suspensions does not require any additional patterning and masking of the substrate and allows for a locally defined deposition of sensing layers so that micromachined silicon-based transducer can also be coated using pre-processed metal- 
oxide powders. An extremely good control of the properties of the paste or suspension used for the deposition process is mandatory to ensure good reproducibility. The drop-deposition method is industrially used for the deposition of metal-oxide films on micromachined platforms (www.appliedsensor.com). The applicability of the drop-deposition method to CMOS-based gas-sensor systems will be demonstrated in the next section.

\section{Gas sensor microsystems and CMOS-based gas sensor microsystems}

A new generation of miniaturized metal-oxide based sensors has been realized by combining micromachined sensor platforms, electronics and smart features, as well as nanotechnologically fabricated sensitive layers on a single chip. A brief description of this monolithic sensor realization and associated issues and limitations is given, whilst the key technologies used for sensitive layer preparation and deposition have been discussed in the previous sections.

A monolithic microhotplate-based sensor system generally consists of the microhotplate itself and dedicated sensor and control electronics on the same chip. (see cross-sectional schematic in Figure 3b). The electronics include, e.g., a temperature controller, driving and read-out circuitry for the different sensor components (temperature sensor and control, resistance measurement of the sensitive layer), signal-conditioning units, and, in some cases, a first-stage data processing module or an embedded data transmission interface (Graf et al., 2004b).

The currently dominant and well-established technology to fabricate integrated circuits is the CMOS technology. The integration of microhotplates with electronics in CMOS technology is particularly challenging, since the metal-oxide operating temperatures of $250-400^{\circ} \mathrm{C}$ are much higher than the temperature specifications for common integrated circuits (between -20 and $150^{\circ} \mathrm{C}$ ). In a monolithic system transducer and circuitry are integrated on a single chip, whereas in a hybrid system, there are separate circuitry and sensor chips. The advantages and drawbacks of hybrid versus monolithic systems have been discussed in detail in literature (Hierlemann \& Baltes, 2003a), so that only a few key points shall be mentioned here. The main disadvantage of monolithic systems is their limitation to available process-specific materials and microtechnological process steps, since the transducer fabrication has to be compatible with the microelectronics fabrication. In most cases, the transducer fabrication is realized in post-processing steps after, e.g., the CMOS microelectronics fabrication process. Interdisciplinary expertise (e.g., physics, material science, electrical engineering, chemistry) is required for the system development, which is rather complex.

Monolithic sensor systems offer advantages such as good signal fidelity due to on-chip signal processing, low power consumption as a consequence of the overall system miniaturization, and reduced packaging efforts since only one chip has to be packaged. Integration of an on-chip serial data transmission interface further reduces the number of bonding wires, especially in the case of an integrated multi-sensor array. Taking into account the mass-production facilities with established microelectronic and microtechnological processes, commercialization of monolithic systems appears to be straightforward and cost-effective. With regard to the sensor performance, on-chip amplification and conditioning of small sensor signals are important advantages. The degree of miniaturization that can be achieved in monolithic implementations leads to very small overall sensor system dimensions, which entails small gas volumes, i.e., short gas sensor response and recovery times. In most publications to date, however, microhotplates are still realized as discrete sensors and are read out by conventional measurement equipment or by means of separate dedicated electronics.

Many microhotplate devices have been denoted to be 'CMOS-compatible', this term, however, is not clearly defined. In most cases 'CMOS-compatible' means, that CMOS materials have been used, or the design can be used within a modified CMOS process. As modifications in industrial CMOS processes are difficult to implement, two main approaches have been pursued so far. One approach relies on an open process window for the sensor fabrication, so that the post-CMOS formation of the microhotplate is as much as possible decoupled from the CMOS-process. CMOS-compatible in this case means, that the CMOS postprocessing steps do not require temperature steps at temperatures higher than $400^{\circ} \mathrm{C}$, since the 


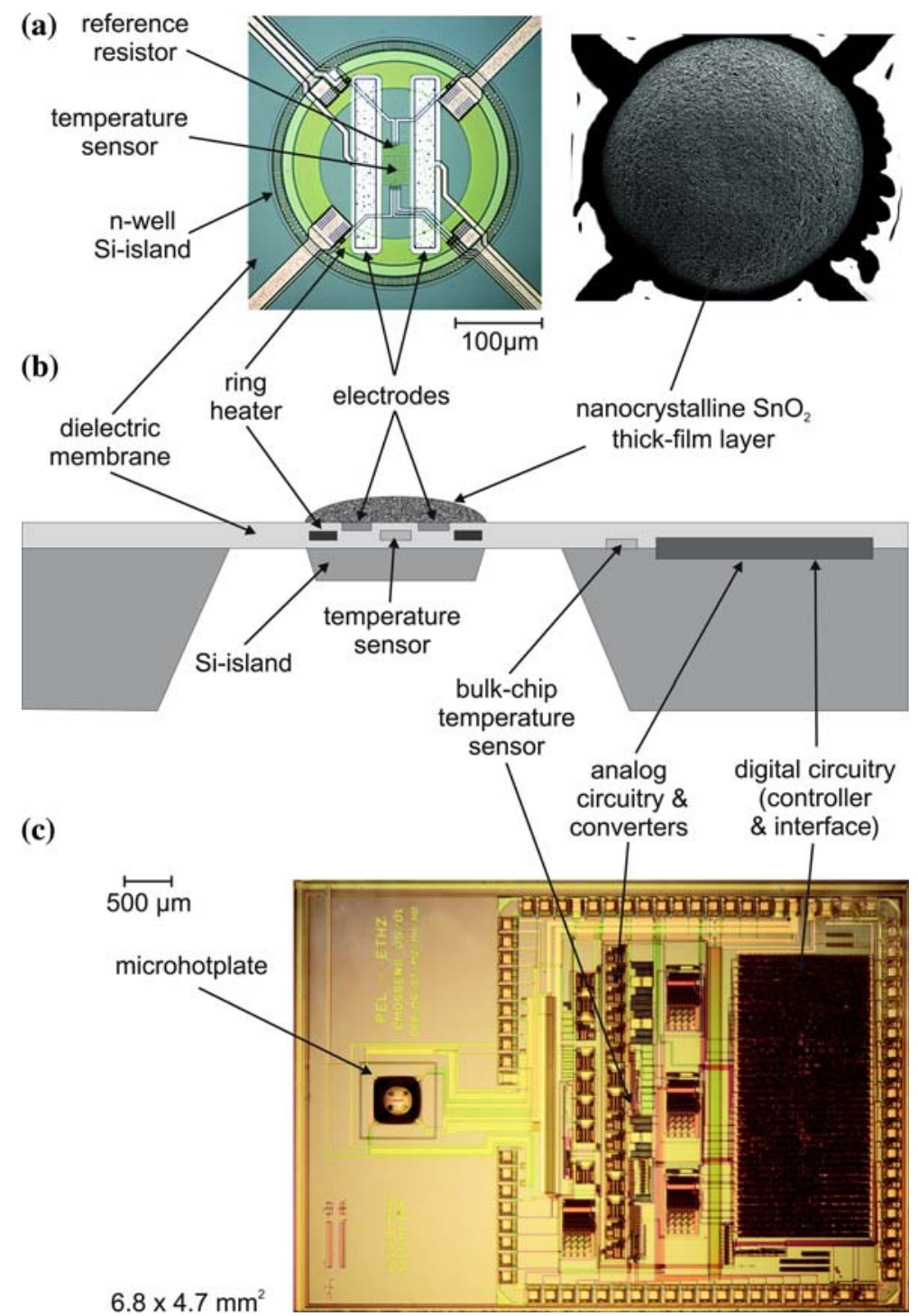

Figure 3. Monolithic metal-oxide-based gas sensor system in CMOS technology: (a) Close-up of the microhotplate (left side) and SEM-micrograph of a microhotplate with a drop-coated nanocrystalline thick-film layer (right side). (b) Cross-sectional schematic of the heated area of the sensor chip (c) Micrograph of the CMOS-based overall sensor system chip featuring microhotplates and circuitry (Graf et al., 2004b).

CMOS metallization might otherwise degrade, and the electronics characteristics may be altered. Therefore, LPCVD (low-pressure chemical vapor deposition) oxides and nitrides with typical deposition temperatures of $700-800^{\circ} \mathrm{C}$ are not applicable. The sensor development is mostly independent of the complex CMOS-process. Several groups pursued such an approach proposed, e.g., by Müller et al. (2003). A bridge-like hotplate struc- ture has been fabricated using SOI (SOI: silicon on insulator) silicon wafers (Friedberger et al., 2003). The sensitive layer has been produced by a RGTO (RGTO: rheotaxial growth and oxidation) method, where metallic tin is deposited and subsequently oxidized at $600^{\circ} \mathrm{C}$ to form nanogranular $\mathrm{SnO}_{2}$ (Friedberger et al., 2003; Müller et al., 2003). Another sensor system featuring four different sensitive layers on a single microhotplate was pre- 
sented recently (Wöllenstein et al., 2003a; Bota et al., 2004). In both cases, full monolithic integration of transducer or sensor structures and electronics has not been demonstrated.

The other method includes the pre-definition of the microhotplate in the CMOS-process. The microhotplate is then finalized by additional postprocessing steps after the CMOS process. Examples include a spider-like microhotplate structure (Suehle et al., 1993) and a membrane-type microhotplate developed (Graf et al., 2004a; see Figure 3). A microhotplate fabricated in siliconon-insulator (SOI)-CMOS technology with a transistor instead of a resistor as heating element has been presented (Udrea et al., 2001; Covington et al., 2002). A microhotplate featuring a transistor heater was also realized in conventional CMOS technology (Graf et al., 2005b). These transistorheated devices potentially can also be monolithically integrated with the necessary associated circuitry (Graf et al., 2004c).

The temperature limit of approximately $400^{\circ} \mathrm{C}$ as a consequence of using CMOS technology limits the number of suitable sensitive materials and imposes constraints on the deposition methods. However, this temperature limit can be circumvented by locally heating the microhotplate instead of processing the whole chip or wafer in an oven. The temperature limit holds for the circuitry part, so that heating of the microhotplate only allows for applying higher temperatures to sensitive-layer processing and annealing (Wöllenstein et al., 2003a; Barrettino et al., 2004). It has to be noted, however, that this local heating method requires establishing electrical connections to the hotplate heaters of each individual sensor device so that batch fabrication is not that easy to realize.

As already mentioned, most microhotplatebased gas sensors have been realized as multi-chip solutions with separate transducer and electronics chips. The multi-chip approach offers the possibility to develop microhotplates independently from the CMOS process and to use a wide variety of materials and structures. An example of a hybrid sensor system comprising a tin-oxidecoated microhotplate, an alcohol sensor, a humidity sensor and an associated ASIC chip (Application-specific Integrated Circuit) has been presented (Cardinali et al., 1997). More recent developments include an interface-circuitry chip for metal-oxide gas sensors and an architecture of an on-chip driving circuitry for a gas sensor array (Ruedi et al., 2001; Mo et al., 2002).

First monolithic devices have been also presented recently. A chip developed at the National Institute of Standards (NIST), USA hosts an array of microhotplates integrated with transistor switches and a readout amplifier for the gas-sensor signal (Afridi et al., 2002). The first monolithic realization of a microhotplate and electronics in a system architecture contains an analog temperature controller and a logarithmic converter for the readout of the sensor values (Graf et al., 2004a).

An example for a more advanced analog/digital monolithic system is shown in Figure 3 (for details see Graf et al., 2004b). The figure has three components: Figure 3(a) shows a close-up of the microhotplate featuring the typical functional elements. The heater has a circular-shape that matches the droplet shape of the sensitive layer. On the right-hand side of Figure 3a, a SEM micrograph of a drop-coated microhotplate is depicted. Figure $3 \mathrm{~b}$ shows a cross-sectional schematic of the monolithic sensor system. Its fabrication relies on an industrial CMOS process with subsequent micromachining steps. Divers thin-film layers, which can be used for electrical insulation and passivation, are available in the CMOS process. They are denoted as 'dielectric layers' and include several silicon-oxide layers such as the thermal field oxide, contact oxide, and the intermetal oxide, as well as a silicon-nitride layer that serves as passivation. All these materials exhibit characteristically low thermal conductivities, so that a membrane, which consists of only the dielectric layers, provides excellent thermal insulation between the bulk chip and a heated membrane area. The heated area features a resistive heater, a temperature sensor, and electrodes to contact the deposited sensitive metal oxide. An additional temperature sensor is integrated close to the circuitry on the bulk chip to monitor the overall chip temperature. The membrane is released by etching away the silicon underneath the dielectric layers. Depending on the micromachining procedure, it is possible to leave a silicon island underneath the heated area. Such an island can serve as a heat spreader and also mechanically stabilizes the membrane.

Figure $3 \mathrm{c}$ shows a micrograph of the overall chip. Three main parts are distinguishable: (i) the microhotplate, (ii) analog circuitry including the analog-to-digital and digital-to-analog converters 
and (iii) digital circuitry. The latter includes a programmable digital temperature controller and a digital interface. This interface enables the setting of the hotplate temperatures and the readout of all relevant signals such as the gas sensor signal, the microhotplate temperature, and the chip temperature. The integrated logarithmic converter that is connected to the resistance readout of the sensitive layer provides a first-order signal linearization. Furthermore, the converter helps to deal with the potentially large metal-oxide resistance range from $1 \mathrm{k} \Omega$ up to $100 \mathrm{M} \Omega$.

The most recent devices (Graf et al., 2004c) have been developed with the aim to take full advantage of combining electronics and transducers on a single chip using the CMOS-MEMS approach. The chip features three transistor-heated microhotplates (Graf et al., 2005b) and fully digital temperature controllers as well as a digital interface. The chip is a standalone sensor system so that no external equipment is needed for operation. The system can be directly connected to an USB interface, which then provides the $5 \mathrm{~V}$ power supply and represents the communication interface between chip and, e.g., a laptop or palmtop computer. The microhotplates of this digital sensor array are covered with three nanocrystalline tin-oxide thick films that are doped to a different extent with $\mathrm{Pd}$ (undoped, 0.2 , and $3 \mathrm{wt} \% \mathrm{Pd}$ ). The layers have been deposited again by a drop-deposition method as has been described previously (see also Briand et al., 2000). The microsystem shows large responses upon exposure to environmentally relevant gases such as $\mathrm{CO}, \mathrm{CH}_{4}$, and $\mathrm{NO}_{2}$. The chip also represents a micro-platform for investigating the sensing characteristics of new materials, since arbitrary temperature profiles can be applied and their effect on analyte discrimination can be evaluated.

\section{Conclusions and outlook}

In the near future, high-performance metal-oxidebased gas sensor systems will be developed that will be miniaturized to an even larger degree and that will feature complex on-chip electronics and, possibly, additional data processing features. Within these research and development efforts three main thrusts have been identified:
(1) The development of microhotplates that can provide higher temperatures, that feature longer lifetime and offer less power consumption. These microhotplates also will be used as a research tool in material science (Barrettino et al., 2004), and for extended characterizations of gas-sensitive layers (Panchapakesan et al., 2001; Semancik et al., 2001).

(2) The development of complex on-chip sensor electronics and system architectures that include sensor control, sensor readout, signal conditioning and self-calibration features as well as signal processing and signal evaluation units. The electronics development will benefit both, monolithic and hybrid sensor systems.

(3) The development of nanoparticle-based sensitive layers that feature high sensitivity and sufficient long-term stability. The production of such nanoparticles for sensing applications and the development of suitable deposition methods for micromachined substrates remain challenging, in particular for monolithic devices, as a consequence of the requirements and limitations imposed by the adopted microsensor/microelectronics technology and the respective fabrication steps.

Future research will also include the synthesis of nanoparticles with various compositions and shapes, the modification of the sensor response behavior by using catalytic additives, and the fabrication of stable nanoporous layers. A solution to the well-documented problem of low selectivity of metal oxides is the application of sensor arrays, i.e., the simultaneous use of different sensing materials and a subsequent mathematical treatment of the recorded data set (multi-component analysis or pattern recognition algorithms). The use of sensor arrays entails the deposition of different materials on a single microchip, which is even more difficult to realize. Therefore, new ideas for the deposition and structuring of metal-oxide sensitive layers have to be developed in order to realize highly integrated and miniaturized sensor systems.

\section{References}

Afridi M.Y., J.S. Suehle, M.E. Zaghloul, D.W. Berning, A.R Hefner, R.E. Cavicchi, S. Semancik, C.B. Montgomery \& C.J. Taylor, 2002. A monolithic CMOS microhotplate-based gas sensor system. IEEE Sens. J. 2, 644-655. 
Aronova M.A., K.S. Chang, I. Takeuchi, H. Jabs, D. Westerheim, A. Gonzalez-Martin, J. Kim \& B. Lewis, 2003. Combinatorial libraries of semiconductor gas sensors as inorganic electronic noses. Appl. Phys. Lett. 83(6), $1255-1257$.

Bârsan N., M. Schweizer-Berberich \& W. Göpel, 1999. Fundamental and practical aspects in the design of nanoscaled $\mathrm{SnO}_{2}$ gas sensors: A status report. Fresenius' J. Anal. Chem. 365(4), 287-304.

Bârsan N. \& U. Weimar, 2001. Conduction model of metaloxide gas sensors. J. Electroceram. 7(3), 143-167.

Bielanski A., J. Deren \& J. Haber, 1957. Electric conductivity and catalytic activity of semiconducting oxide catalysts. Nature 179, 668-679.

Barrettino D., M. Graf, W.H. Song, K.-U. Kirstein, A. Hierlemann \& H. Baltes, 2004. Hotplate-based monolithic CMOS microsystems for gas detection and material characterization for operating temperatures up to $500^{\circ} \mathrm{C}$. IEEE J. Solid-State Circ. 39, 1202-1207.

Bota S.A., A. Dieguez, J.L. Merino, R. Casanova, J. Samitier \& C. Cané, 2004. A monolithic interface circuit for gas sensor arrays: Control and measurement. Analog Integr. Circuits Signal Process. 40(2), 175-184.

Briand D., A. Krauss, B. van der Schoot, U. Weimar, N. Bârsan, W. Göpel \& N.F. de Rooij, 2000. Design and fabrication of high-temperature micro-hotplates for dropcoated gas sensors. Sens. Actuat. B: Chem. 68(1-3), 223-233.

Brinker C. \& G. Scherer,. 1990. Sol-Gel Science: The Physics and Chemistry of Sol-Gel Processing. London: Academic Press 502.

Cardinali G.C., L. Dori, M. Fiorini, I. Sayago, G. Fagila, C. Perego, G. Sberveglieri, V. Liberali, F. Maloberti \& D. Tonietto, 1997. A smart sensor system for carbon monoxide detection. Analog Integr. Circ. Signal Process. 14, 275-296.

Cavicchi R.E., J.S. Suehle, K.G. Kreider, B.L. Shomaker, J.A. Small, M. Gaitan \& P. Chaparala, 1995. Growth of $\mathrm{SnO}_{2}$ films on micromachined hotplates. Appl. Phys. Lett. 66(7), 812-814.

Cavicchi R.E., R.M. Walton, M. Aquino-Class, J.D. Allen \& B. Panchapakesan, 2001. Spin-on nanoparticle tin oxide for microhotplate gas sensors. Sens. Actuat. B: Chem. B77(1-2), $145-154$.

Cerdà J., A. Cirera, A. Vila, A. Cornet \& J.R. Morante, 2001. Deposition on micromachined silicon substrates of gas sensitive layers obtained by a wet chemical route: a $\mathrm{CO} / \mathrm{CH}_{4}$ high performance sensor. Thin Solid Films 391(2), 265-269.

Chung W.Y., J.W. Lim, D.D. Lee, N. Miura \& N. Yamazoe, 2000. Thermal and gas-sensing properties of planar-type micro gas sensor. Sens. Actuat. B: Chem. 64(1-3), 118-123.

Covington J.A., F. Udrea \& J.W. Gardner, 2002. Resistive gas sensor with integrated MOSFET micro hot-plate based on an analogue SOI CMOS process. Proc. IEEE Conference on Sensors 2002, Orlando, FL, USA, 1389-1394.

Demarne V. \& A. Grisel, 1993. A new tin oxide low temperature deposition technique for integrated gas sensors. Sens. Actuat. B: Chem. 15(1-3), 63-67.
Ding J.H., T.J. McAvoy, R.E. Cavicchi \& S. Semancik, 2001. Surface state trapping models for $\mathrm{SnO}_{2}$-based microhotplate sensors. Sens. Actuat. B: Chem. 77(3), 597-613.

Eranna G., B.C. Joshi, D.P. Runthala \& R.P. Gupta, 2004. Oxide materials for development of integrated gas sensors - a comprehensive review. Crit. Rev. Solid State Mater. Sci. 29(3-4), 111-188.

Fau P., M. Sauvan, S. Trautweiler, C. Nayral, L. Erades, A. Maisonnat \& B. Chaudret, 2001. Nanosized tin oxide sensitive layer on a silicon platform for domestic gas applications. Sens. Actuat. B: Chem. 78(1-3), 83-88.

Friedberger A., P. Kreisl, E. Rose, G. Müller, G. Kuhner, J. Wöllenstein \& H. Böttner, 2003. Micromechanical fabrication of robust low-power metal oxide gas sensors. Sens. Actuat. B: Chem. 93(1-3), 345-349.

Gardner J.W., A. Pike, N.F. de Rooij, M. Koudelka-Hep, P.A. Clerc, A. Hierlemann \& W. Göpel, 1995. Integrated array sensor for detecting organic solvents. Sens. Actuat. B: Chem. 26(1-3), 135-139.

Gong J., Q. Chen, W. Fei \& S. Seal, 2004. Micromachined nanocrystalline $\mathrm{SnO}_{2}$ chemical gas sensors for electronic nose. Sens. Actuat. B: Chem. B102(1), 117-125.

Graf M., D. Barrettino, M. Zimmermann, A. Hierlemann, H. Baltes, S. Hahn, N. Bârsan \& U. Weimar, 2004a. CMOS monolithic metal-oxide sensor system comprising a microhotplate and associated circuitry. IEEE Sens. J. 4(1), 9-16.

Graf M., D. Barrettino, S. Taschini, C. Hagleitner, A. Hierlemann \& H. Baltes, 2004b. Metal oxide-based monolithic complementary metal oxide semiconductor gas sensor microsystem. Anal. Chem. 76(15), 4437-4445.

Graf M., U. Frey, P. Reichel, S. Taschini, N. Bârsan U. Weimar \& A. Hierlemann, 2004c. In: Proc. IEEE Conference on Sensors 2004, Vienna, Austria, pp. 776-779.

Graf M., R. Jurischka, D. Barrettino \& A. Hierlemann, 2005a. $3 \mathrm{D}$ nonlinear modeling of microhotplates in CMOS technology for use as metal-oxide-based gas sensors. J. Micromech. Microeng. 15, 190-200.

Graf M., S.K. Müller, D. Barrettino \& A. Hierlemann, 2005b. Transistor heater for microhotplate-based metal-oxide microsensors. IEEE Electron Device Lett. 26(5), 295-297.

Guidi V., M.A. Butturi, M.C. Carotta, B. Cavicchi, M. Ferroni, C. Malagu, G. Martinelli, D. Vincenzi, M. Sacerdoti \& M. Zen, 2002. Gas sensing through thick film technology. Sens. Actuat. B: Chem. 84(1), 72-77.

Heilig A., N. Bârsan, U. Weimar \& W. Göpel, 1999. Selectivity enhancement of $\mathrm{SnO}_{2}$ gas sensors: Simultaneous monitoring of resistances and temperatures. Sens. Actuat. B: Chem. 58(1-3), 302-309.

Heilig A., N. Bârsan, U. Weimar, M. Schweizer-Berberich, J.W. Gardner \& W. Göpel, 1997. Gas identification by modulating temperatures of $\mathrm{SnO}_{2}$-based thick film sensors. Sens. Actuat. B: Chem. 43(1-3), 45-51.

Heule M. \& L.J. Gauckler, 2001. Gas sensors fabricated from ceramic suspensions by micromolding in capillaries. Advanced Mater. 13(23), 1790-1793.

Heule M. \& L.J. Gauckler, 2003. Miniaturised arrays of tin oxide gas sensors on single microhotplate substrates 
fabricated by micromolding in capillaries. Sens. Actuat. B: Chem. 93(1-3), 100-106.

Heiland G., 1957. Zum Einfluss von Wassershoff auf die elektrische Leitfahzkeit an der Oberfläche von Zinkoxydkristallen. Zeitschrift für Physik 148(1), 15-27.

Hierlemann A. \& H. Baltes, 2003a. CMOS-based chemical microsensors. Analyst 128(1), 15-28.

Hierlemann A., O. Brand, C. Hagleitner \& H. Baltes, 2003b. Microfabrication techniques for chemical/biosensors. Proceedings of the IEEE 91(6), 839-863.

Jimenez I., A. Cirera, J. Folch, A. Cornet \& J.R. Morante, 2001. Innovative method of pulverisation coating of prestabilized nanopowders for mass production of gas sensors. Sens. Actuat.B: Chem. 78(1-3), 78-82.

Jimenez I., A. Cirera, A. Cornet, J.R. Morante, I. Gracia \& C. Cané, 2002. Pulverisation method for active layer coating on microsystems. Sens. Actuat. B: Chem. 84(1), $78-82$.

Kennedy M.K., F.E. Kruis, H. Fissan, B.R. Mehta, S. Stappert \& G. Dumpich, 2003. Tailored nanoparticle films from monosized tin oxide nanocrystals: Particle synthesis, film formation, and size-dependent gas-sensing properties. J. Appl. Phys. 93(1), 551-560.

Kodas, T.T. \& M.J. Hampden-Smith, 1999. Aerosol Processing of Materials. Wiley- $\mathrm{VCH}, 680 \mathrm{pp}$.

Llobet E., P. Ivanov, X. Vilanova, J. Brezmes, J. Hubalek, K. Malysz, I. Gracia, C. Cane \& X. Correig, 2003. Screenprinted nanoparticle tin oxide films for high-yield sensor microsystems. Sens. Actuat. B: Chem. B96(1-2), 94-104.

Mädler, L., A. Roessler, S.A. Pratsinis, T. Sahm, A. Gurlo, N. Bârsan \& U. Weimar, 2005. Direct formation of highly porous gas-sensing films by in-situ thermophoretic deposition of flame-made $\mathrm{Pt} / \mathrm{SnO}_{2}$ nanoparticles. Sens. Actuat. B: Chem, in press.

Madou, M.J. \& S.R. Morrison, 1989. Chemical Sensing with Solid-State Devices, Academic Press, Inc., Boston, MA $556 \mathrm{pp}$.

Marek J., H.-P. Trah, Y. Suzuki \& I. Yokomori, eds., 2003. Sensors for Automotive Technology. VCH, Weinheim, p. 562 .

Mitzner K.D., J. Sternhagen \& D.W. Galipeau, 2003. Development of a micromachined hazardous gas sensor array. Sens. Actuat. B: Chem. B93(1-3), 92-99.

Müller G., A. Friedberger, P. Kreisl, S. Ahlers, O. Schulz \& T. Becker, 2003. A MEMS toolkit for metal-oxide-based gas sensing systems. Thin Solid Films 436(1), 34-45.

Mo Y.W., Y.Z. Okawa, K.J. Inoue \& K. Natukawa, 2002. Low-voltage and low-power optimization of micro-heater and its on-chip drive circuitry for gas sensor array. Sens. Actuat. A: Phys. 100, 94-101.

Panchapakesan B., D.L. DeVoe, M.R. Widmaier, R. Cavicchi \& S. Semancik, 2001. Nanoparticle engineering and control of tin oxide microstructures for chemical microsensor applications. Nanotechnology 12, 336-349.

Pinna N., G. Neri, M. Antonietti \& M. Niederberger, 2004. Gas sensors: Nonaqueous synthesis of nanocrystalline semiconducting metal oxides for gas sensing. Angew. Chem., Int. Edn. 43(33), 4345-4349.
Puigcorbe J., A. Cirera, J. Cerda, J. Folch, A. Cornet \& J.R Morante, 2002. Microdeposition of microwave obtained nanoscaled $\mathrm{SnO}_{2}$ powders for gas sensing microsystems. Sens. Actuat. B: Chem. 84(1), 60-65.

Reed J.S., 1986. Introduction to the Principles of Ceramic Processing. Wiley Interscience, New York.

Riviere B., J.P. Viricelle \& C. Pijolat, 2003. Development of tin oxide material by screen-printing technology for micromachined gas sensors. Sens. Actuat. B: Chem. 93(1-3), 531-537.

Rothschild A. \& Y. Komem, 2004. The effect of grain size on the sensitivity of nanocrystalline metal-oxide gas sensors. J. Appl. Phys. 95(11), 6374-6380.

Ruedi P.F., P. Heim, A. Mortara, E. Franzi, H. Oguey \& X. Arreguit, 2001. Interface circuit for metal-oxide gas sensor. Digest IEEE Custom Integr. Circ. Conf. 2001, 109-112.

Sahm T., L. Mädler, A. Gurlo, N. Bârsan, S.E. Pratsinis \& U. Weimar, 2004. Flame spray synthesis of tin dioxide nanoparticles for gas sensing. Sens. Actuat. B: Chem. 98(2-3), $148-153$.

Savage N.O., S. Roberson, G. Gillen, M.J. Tarlov \& S. Semancik, 2003. Thermolithographic patterning of sol-gel metal oxides on micro hot plate sensing arrays using organosilanes. Anal. Chem. 75(17), 4360-4367.

Seiyama T., A. Kato, K. Fujiishi \& M. Nagatani, 1962. A new detector for gaseous components using semiconductive thin films. Anal. Chem., 34(11), 1502.

Semancik S., R.E. Cavicchi, K.G. Kreider, J.S. Suehle \& P. Chaparala, 1996. Selected-area deposition of multiple active films for conductometric microsensor arrays. Sens. Actuat. B: Chem. 34(1-3), 209-212.

Semancik S. \& R. Cavicchi, 1998. Kinetically controlled chemical sensing using micromachined structures. Acc. Chem. Res. 31(5), 279-287.

Semancik S., R.E. Cavicchi, M.C. Wheeler, J.E. Tiffany, G.E. Poirier, R.M. Walton, J.S. Suehle, B. Panchapakesan \& D.L. DeVoe, 2001. Microhotplate platforms for chemical sensor research. Sens. Actuat. B: Chem. 77(1-2), 579-591.

Sheng L.Y., Z.N. Tang, J. Wu, P.C.H. Chan \& J.K.O. Sin, 1998. A low-power CMOS compatible integrated gas sensor using maskless tin oxide sputtering. Sens. Actuat. B: Chem. 49(1-2), 81-87.

Shimizu Y., T. Hyodo \& M. Egashira, 2004. Meso- to macroporous oxides as semiconductor gas sensors. Catal. Surv. Asia 8(2), 127-135.

Shirahata N. \& A. Hozumi, 2005. Etchingless microfabrication of a thick metal oxide film on a flexible polymer substrate. Chem. Mater. 17(1), 20-27.

Simon I., N. Bârsan, M. Bauer \& U. Weimar, 2001. Micromachined metal oxide gas sensors: opportunities to improve sensor performance. Sens. Actuat. B: Chem. 73(1), $1-26$.

Stankova M., P. Ivanov, E. Llobet, J. Brezmes, X. Vilanova, I. Gracia, C. Cane, J. Hubalek, K. Malysz \& X. Correig, 2004. Sputtered and screen-printed metal oxide-based integrated micro-sensor arrays for the quantitative analysis of gas mixtures. Sens. Actuat. B: Chem. B103(1-2), 23-30. 
Su M., S.Y. Li \& V.P. Dravid, 2003. Miniaturized chemical multiplexed sensor array. J. Am. Chem. Soc. 125(33), 9930 9931.

Suehle J.S., R.E. Cavicchi, M. Gaitan \& S. Semancik, 1993. Tin oxide gas sensor fabricated using CMOS microhotplates and in-situ processing. IEEE Electr. Device Lett. $14,118-120$.

Taguchi, N., 1971. Gas detecting device. U.S. Patent. 3,631,436.

Taylor C.J. \& S. Semancik, 2002. Use of microhotplate arrays as microdeposition substrates for materials exploration. Chem. Mater. 14(4), 1671-1677.

Pearce T.C., S. Susan Schiffman, H. Troy Nagle \& J.W. Gardner, eds, 2004. Handbook of Machine Olfaction: Electronic Nose Technology. VCH, Weinheim.

Tsai P.P., I.C. Chen \& C.J. Ho, 2001. Ultralow power carbon monoxide microsensor by micromachining techniques. Sens. Actuat. B: Chem. 76(1-3), 380-387.

Udrea F., J.W. Gardner, D. Setiadi, J.A. Covington, T. Dogaru, C.C. Lua \& W.I. Milne, 2001. Design and simulations of SOI-CMOS micro-hotplate gas sensors. Sens. Actuat. B: Chem. 78, 180-190.

Vincenzi D., M.A. Butturi, V. Guidi, M.C. Carotta, G. Martinelli, V. Guarnieri, S. Brida, B. Margesin, F. Giacomozzi, M. Zen, D. Giusti, G. Soncini, A.A. Vasiliev \& A.V. Pisliakov, 2000. Gas-sensing device implemented on a micromachined membrane: A combination of thick-film and very large scale integrated technologies. J. Vacuum Sci. Technol. B 18(5), 2441-2445.

Vincenzi D., M.A. Butturi, V. Guidi, M.C. Carotta, G. Martinelli, V. Guarnieri, S. Brida, B. Margesin, F. Giacomozzi, M. Zen, G.U. Pignatel, A.A. Vasiliev \& A.V. Pisliakov, $2001 \mathrm{a}$. Development of a low-power thick-film gas sensor deposited by screen-printing technique onto a micromachined hotplate. Sens. Actuat. B: Chem. 77(1-2), 95-99.

Vincenzi D., M.A. Butturi, M. Stefancich, C. Malagu, V. Guidi, M.C. Carotta, G. Martinelli, V. Guarnieri, S. Brida, B. Margesin, F. Giacomozzi, M. Zen, A.A. Vasiliev \& A.V. Pisliakov, 2001b. Low-power thick-film gas sensor obtained by a combination of screen printing and micromachining techniques. Thin Solid Films 391(2), 288-292.

Williams D.E., 1987. In: Moseley P.T., Totfield B.C. and Hilger A. eds. Solid-State Gas Sensors. Philadelphia, Bristol \& Philadelphia, pp. 71-123.

Wöllenstein J., J.A. Plaza, C. Cane, Y. Min, H. Böttner \& H.L. Tuller, 2003a. A novel single chip thin film metal oxide array. Sens. Actuat. B: Chem. 93(1-3), 350-355.

Wöllenstein, J., R. Stich, E. Moretton, H. Böttner, J. Beardon \& P. Smith, 2003b. In: Proceedings of the 17th Eurosensors conference, Guimaraes, Portugal, pp. 364-365.

Xu C., J. Tamaki, N. Miura \& N. Yamazoe, 1991. Grain-size effects on gas sensitivity of porous $\mathrm{SnO}_{2}$-based elements. Sens. Actuat. B: Chem. 3(2), 147-155. 